each confine himself to his own branch, at the same time recognising the importance of our discovery; and Herr König, in a paper published in the Berichte, xii. 97, referring to our first paper, says : "Es ist der erste glatte Uebergang der Chinaalkaloïde in eine jedenfalls einfachere Substanz-das Pyridin."

WILLIAM RAMSAY

Glasgow University

JAMES J. DOBBIE

\section{The Temperature of the Breath}

Dr. DuDGEon's first letter under this heading contained the suggestion of a friend that his enigmatical thermometric readings were to be accounted for by the high temperature " caused by the conden ation of the moisture of the breath by the silk hand kerchief." The discussion that followed has not only brough us back to this solution, but has also furnished us with an authoritative expression of opinion that the clinical thermometer is not sensitive to pressure. F. J. M. P. first hinted the contrary prop ssition only to have it thrust aside by Dr. Dudgeon with blunt denial, neglected by Dr. Roberts, and finally discarded by himself for no other apparent reason than that aqueous vapour in condensing liberates heat. Yet I venture to as ert that readings as high as any obtainable by Dr. Dudgeon's method, less the pressure, can be obtained by a very similar mode of experimenting, without the developed heat : $\mathrm{r}$. If the bulb of a thermometer, protected by paper or other nonconductor, be squeezed in an intermittent manmer between finger and thumb, it will be found that the mercury can readily be made to dance up and down through about a degree on the scale with a celerity not attributable to changes of temperature. 2. If eighteen inches of cotton thread be tightly wound about the bulb, on immersing the thermometer in water it will exaggerate the temperature sometimes by as many as $12^{\circ} \mathrm{F}$. 3. If a tube filled with caczo butter be substituted for the thermometer the butter beneath the thread will be longer in melting than that in other portions of the tube, a result which I think proves that the high readings of experiment No. 2 are not temperature, but (in the light of No. I) pressure readings.

My chief object in writing is to protest on general grounds again th the treatment accorded to F. J. M. P.'s suggestion, but at the same time I wish to express my opinion that Dr. Roberts' argument would have been strengthened by giving heed to it, for I see nothing in his account of the interrupted experiment not explainable on the pressure hypothesis al ne, the descending series of readings being perchance due to a yielding of the wrappings under prolonged tension. On the other hand $I$ have to thank this omission on Dr. Roberts' part for having induced me to test the subject for myself, and thus experience, in repeating his experiment, the rare pleasure of scientific surprise at seeing the index mount higher and higher above the level of my expectations under conditions which left no doubt as to the cause being a rise of temperature. Dr. Dudgeon has done good service by directing attention to a simple experiment which, properly interpreted, throws new light on the philosophy of clothes, and should prove a telling shaft in the quiver of popula science.

Islington, December 26,1880

IN the number of NATURE which reached Madras after the departure of the inail conveying my letter of the $9^{\text {th }}$ inst., I was glad to read Dr. W. Roberts' abundantly full and lucid explanation of the heat produced by breathing on thermometers enveloped in hygroscopic substances. He has, by a very simple method, confirmed the view endorsed in my communication in NATURE, vol, xxiii. p. 534 .

That the effects of friction and of compression of air are so slight that they may be disregarded, has been proved; and the rise bas been clearly traced to absorption of aqueous vapcur. It has yet to be determined how much of this heat may be accounted for by the reduction of aqueous vapour to the fluid state, and how much by capillary action and absor tion of water, with or without chemical union, and its reduction to the soli.1 state-al of which may be included in hygroscopic action. This determination would involve some intricate inve tigations which some scientific sfecialist may perhaps find leisure to undertake. That more than simple vapour condensation is concerned in the production of hygroscopic heat is shown by the rise of temperature on adding water to a non-saturated hygro:cnpic subst ince.
A scientific colleague has suggested to me that some cases of very high axillary temperatures may be explained by the clothing of patients being pressed into the axilla in contact with the thermometer. Thus, by folding a banian round a thermometer placed in the axilla, I registered a temperature above $100^{\circ} \mathrm{F}$. while the tempera ure in the bare axilla was 98.3 . It is evident that recently changed and driad clothing and clothing warmed by the body of a non-perspiring fever patient would have still more effect when pressed clo iely into a hot and moist axilla. Although this point is iuportant mainly to physicians, I venture to draw attention to it through your colimns on account of its connection with the subject of hygro copic heat.

Madras, December I6, I880

C. J. McNally

\section{Distance of Clouds}

I HAVE conveniently determined the distance of passing clouds by a method probably not new, but which I have not seen described.

It consists in ascertaining the velocity with which the shidow of a cloud traverses level ground, which is easily observed, and of course gives the velocity of the cloud itself.

The an rular motion per second of clouds passing overhead is simultaneonsly observed by means of a coarse micrometer in a telescope, or with a theodolite.

The distance is thus obtained with fair app:oximation.

Distance $=\frac{v t 3438}{n}, v$ being the velocity in feet per second, and $n$ the number of minutes of arc described in $t$ seconds.

A distant mirror may be advantageonsly uied in determining the velocity of the shado:v.

\section{EDWIN ClaRK}

\section{Fluke in Calves}

CAN any of your readers account for the following facts?An examination of the liver of some six-weeks-old calves which had never touched any food but their mother's milk showed then to be infested with fully-developed Fluke (Distomx hepatica). It is clear that the presence of these flukes does not admit of the usual explanation, viz., the ingestion with green food or water of mollusca bearing the larva in one of its earlier stages.

I should be grateful if any of your readers could suggest an explanation of the mote in which the fluke entered the liver of the calf. Is it possible that the larva may hive passed into the milk of the mother, and so have entered the stomach of the calf?

It may interest some of your reader; to know that traces of fluke were present in the livers of cattle lately killed when in bigh condition. The fluke had apparently been established in the liver some consi lerable tine previous to the slaughter of the animals, and bad perished on their attaining to a state of high health and vigour.

A. B.

\section{JOHN STENHOUSE, LL.D., F.R.S.}

$\mathrm{N}$ the early morning of the last day of the old year we lost one of the few surviving founders of the Chemical Society, Dr. John Stenhouse. He was born at Glasgow, October 2r, I809, the son of William Stenhouse of the well-known firm of calico-printers, John Stenhouse and Co. of Barrhead. He was educated first at the Grammar School and then at the University of Glasgow, and long resided in his native city. At an early age he turned his attention to chemistry, and diligently studied that science under Graham and Thomson, and subsequently with Liebig at the University of Giessen. When he removed to London, after the failure of the Western Bank of Scotland had deprived him of the fortune bequeathed to him by his father, he became Lecturer on Chemistry in St. Bartholomew's Hospital, London, but was obliged to resign that appointment in 1857 owing to a severe attack of paralysis. Even this affliction however did not discourage him, and after the lapse of a short time he renewed his scientific labours. In I 865 he susceeded Dr. 
Hofmann as non-resident Assayer to the Royal Mint, but was deprived of the appointment by Mr. R. Lowe, who abolished the office in 1870 .

A pupil of Graham and Liebig, he had all their enthusiasm for scientific investigation, and devoted nearly the whole of his time to research work in the domain of organic chemistry: the eminence he attained in this branch of science is fully recognised, but his contributions to our technical knowledge are not so well known. $\mathrm{He}$ was the author of many ingenious and useful inventions in relation to dyeing, sugar manufacture, tanning, \&c., but the greatest and most permanent has been the application of charcoal for disinfecting and deodorising purposes, which took the form of charcoal air-filters for the ventilation of sewers, and the charcoal respirator, the best of all respirators, not only for preventing the deleterious effects of noxious gases in numerous manufacturing operations, but also for the protection of those subject to bronchitis, asthma, and other similar diseases.

It is impossible in our limited space to give even an outline of the numerous investigations which he published during his long scientific career, extending as it did over a space of more than forty years. The results are embodied in about 100 papers, published in various scientific journals, English and foreign ; they relate in great part to what may truly be called "organic chemistry"...the chemistry of carbon compounds formed by organised bodies. John Stenhouse was LL.D. of Aberdeen; a Fellow of the Royal Society, which awarded him the Royal Medal in $187 \mathrm{I}$; one of the founders of the Chemical Society; and a Fellow of the recently-established Institute of Chemistry. Of his personal character those who knew him intimately could never speak too higbly; his death will be felt and mourned not only by his many personal friends, but also by men of science throughout Europe.

\section{WILHELM HEINTZ}

$\mathrm{W}^{\mathrm{B}}$

E recently recorded the death, at Halle, on December r, of Prof. W. Heintz, one of the leading German chemists of our day. He was born at Berlin, November 4 , 1817. His earlier university studies were undertaken with a view of becoming a pharmacist, but this intention was relinquished as the attractions of a more purely scientific career were offered to him. In 1844 he received the doctor's degree at the Berlin University, and two years later he was admitted as privat-docent in the philosophical faculty of the same university. In $185^{\circ}$ he accepted a call to Halle as the successor of the wellknown Marschand; and here, after passing frve years as an extraordinary professor, he was appointed in 1855 to the full professorship of chemistry, and the directorship of the newly-built laboratory, posts which he occupied at the time of his death.

As a teacher and as a guide to students inclined towards chemical research, Prof. Heintz evinced more than ordinary capacity, and for a quarter of a century he has ably maintained the reputation of Halle among the centres of chemical interest in Germany. This reputation is due in no small part to his own personal contributions as an investigator ; for few chemists of our day have manifested such unwearied energy and long-continued application, such thoroughness of work, accuracy of observation, and widespread familiarity with fact and theory as are evinced in Heintz's manifold and diversified researches.

The earlier portion of his career was directed to the solution of problems in physiological chemistry. Among his more important researches in this direction mention should be made of those on the juice of the Galactodendron (1845), on kreatin and kreatinin (1847), on lactic acid in the gastric juice (1849), on the composition of bones, and on cholesterin (I850), on the colouring matter of gall stones (185I), on urinary sediments (1862), and more especially on the animal and vegetable fats. This latter research, extending over a period of about seven years, includes exhaustive studies on the physical properties of the fats, methods of their separation, their chemical constitution and nature, the products of their decomposition, \&c. His careful observations of the melting points and composition of the fatty acids in the pure state and when mixed with each other, form essentially the basis of our present knowledge on this subject, and enabled him at the time to show the composite character of various fats which preceding chemists had regarded as.pure compounds.

In analytical chemistry Heintz devised a variety of methods and modifications of methods, amongst which mention may be made of his contributions on the estimation of sulphur in organic bodies, on the separation of magnesia from the alkalies, on the analysis of ashes (1847), on the determination of urea and uric acid, on the detection of gall ( 1848 ), on the determination of nitrogen (185 1 ), on the estimation of phosphoric acid, and numerous analytical data.

In inorganic chemistry his researches were chiefly confined to studies on a variety of phosphates, on bismuth and uranium salts, on the preparation of cæsium and rubidium compounds (1865), on the combustion of ammonia in oxygen (1864), on the silicates of the alkaline metals, and to the examination of the minerals margarite, stassfurtite, carnallite, aluminite, and boracite, the latter of which he prepared artificially (1860).

It is however in the field of pure organic chemistry that Heintz's discoveries have been most numerous and important. They commence with his investigation on saccharic acid, begun in 1844 and resumed in $1858-1860$, to which we owe a great measure of our knowledge of this acid, and especially of its salts and ethers. This was followed in 1856 by a study on the action of chloride of sulphur on the salts of organic acids, in which he recorded the unvarying and simultaneous formation of chlorides and sulphates at the expense of the organic salts. In 1859 he began his extensive research on glycollic acid, which occupied much of his time until i872, by exposing monochloracetic acid to the action of various sodium alcoholates, obtaining thereby the different ethers of glycollic acid; thus with sodium ethylate:

$$
\mathrm{CH}_{2} \mathrm{Cl} . \mathrm{COOH}+\mathrm{NaOC}_{2} \mathrm{H}_{5}=\mathrm{NaCl}+\underset{\mathrm{COOH}}{\mathrm{C} \mathrm{H}_{2} \cdot \mathrm{OC}_{2} \mathrm{H}_{5}} \text {. }
$$

By means of this prolific reaction he obtained a number of interesting derivatives of the acid in question. Closely allied to them were the acid ethers of glycollic acid, obtained by submitting monoshloracetic ethers to the action of salts, or by acting upon glycollic ethers with such bodies as phosgene or chlorocarbonic ether. Among the other important compounds discovered by him in this group are glycolamide, glycol-ethyl-amide, diglycollic acid-- $\mathrm{O}\left(\mathrm{CH}_{2} . \mathrm{COOH}\right)_{2}$-obtained by the action of sodium hydrate on monochloracetic acid, diglycoll-diamide, diglycollamic acid, \&c. During this same period he made noteworthy investigations on the ethyl-amines, on sulphocyan-acetic acid and its derivatives, on nitrate of ethyl, on ethyl-hydantoïn, on lactic acids, and on the amido-acids obtained from chloropropionic and iodopropionic acids by the action of ammonia. With 1874 commences his last important rejearch-that on the aceton bases, the simplest of which result from the action of ammonia on aceton. While forced to overcome manifold difficulties in the prosecution of this investigation, Heintz succeeded in isolating a number of novel and important compounds, especially interesting from a theoretical point of view. The leading forms embraced in this new group are diacetonamine, triacetonamine; the corresponding alcohol bases diaceton-alcamine and 